\title{
An Improved SF6 System for the FXR Induction Linac Blumlein Switches
}

W.J. DeHope, R. Kihara, K. L. Griffin, M.M. Ong, T.O. Ross

June 20, 2007

Particle Accelerator Conference Albuquerque, NM, United States June 25, 2007 through June 29, 2007 
This document was prepared as an account of work sponsored by an agency of the United States Government. Neither the United States Government nor the University of California nor any of their employees, makes any warranty, express or implied, or assumes any legal liability or responsibility for the accuracy, completeness, or usefulness of any information, apparatus, product, or process disclosed, or represents that its use would not infringe privately owned rights. Reference herein to any specific commercial product, process, or service by trade name, trademark, manufacturer, or otherwise, does not necessarily constitute or imply its endorsement, recommendation, or favoring by the United States Government or the University of California. The views and opinions of authors expressed herein do not necessarily state or reflect those of the United States Government or the University of California, and shall not be used for advertising or product endorsement purposes. 


\title{
AN IMPROVED SF 6 SYSTEM FOR THE FXR INDUCTION LINAC BLUMLEIN SWITCHES*
}

\author{
W.J. DeHope", K.L. Griffin, R. Kihara, M.M. Ong, T. O. Ross \\ Lawrence Livermore National Laboratory, Livermore CA 94550, U.S.A.
}

\begin{abstract}
The now-mature FXR (Flash X-Ray) radiographic facility at Lawrence Livermore National Laboratory will be briefly described with emphasis on its pulsed power system. The heart of each accelerating cell's pulseforming Blumlein is it's sulfur hexafluoride-based triggered closing switch. FXR's recent upgrade to a recirculating $\mathrm{SF}_{6}$ gas reclamation system will be described and the resulting accelerator performance and reliability improvements documented. This was accompanied by a detailed switch breakdown study on FXR's Test Stand and the recent analysis of the resulting statistics will be shown.
\end{abstract}

\section{BACKGROUND}

Although direct application of Faraday's Induction Law as a means to accelerate particles in a circular orbit in a changing magnetic field [1] was utilized early in the history of accelerators, the technique was not successfully applied to linear acceleration at high energy [2] until the mid 1960's. Advances in pulsed power technology [3] have enabled this field to steadily develop. Modern induction linacs find application [4] in fields such as heavy ion fusion, advanced radiography, and advanced $\mathrm{rf}$ sources for next-generation linear colliders.

\section{MOTIVATION}

The Flash X-Ray (FXR) induction linac (see Fig. 1) at Lawrence Livermore National Laboratory (LLNL) is one of the few early [5] linear induction accelerators (LIAs) to still be in daily use at a working radiography user facility. To bring it's spatial resolution capabilities up to the standards of modern radiography LIAs such as DARHT and DARHT-II [6], FXR began an upgrade effort focused on the accelerator, pulsed power, and maintenance. A sizable investment in a new Contained Firing Facility [7] had been made and, along with an aggressive radiographic test schedule, accelerator reliability would become increasingly important.

\section{Switches}

As with any pulsed power system, switches are the heart of energy transfer and pulse compression in FXR. This takes place in 3 stages. First a Marx generator is charged to $\sim 70 \mathrm{kV}$ in a period of $1-3$ seconds. Its $300 \mathrm{kV}$

\footnotetext{
*This work was performed under the auspices of the U.S. Department of Energy by University of California, Lawrence Livermore National Laboratory under Contract W-7405-Eng-48.

\#dehope1@1lnl.gov
}

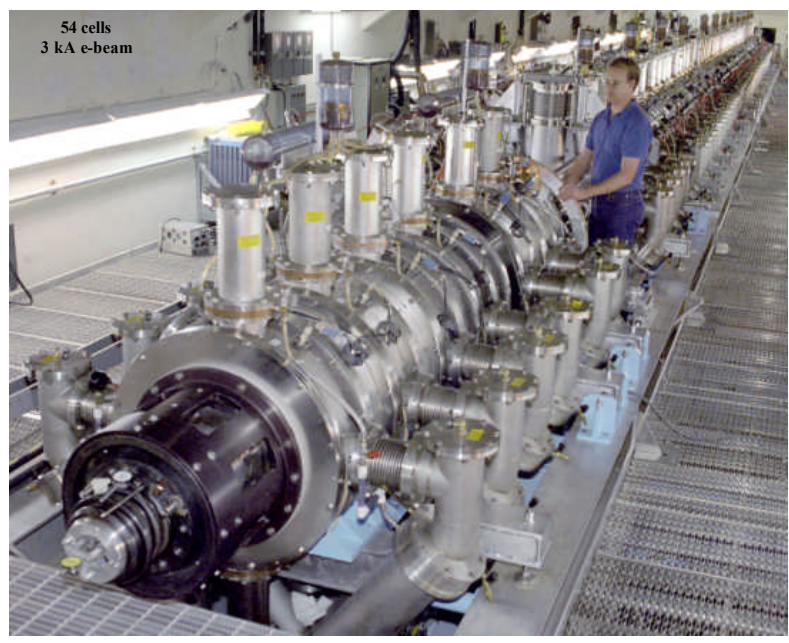

Figure 1: The FXR induction linac at LLNL

output is then resonant-charge transferred to a coaxial Blumlein in a 2 us period. At that point, Blumlein trigger switches discharge the Blumlein into the accelerator cell. There are 54 such high-voltage closing switches in FXR with tight requirements of speed, voltage hold-off, and timing accuracy.

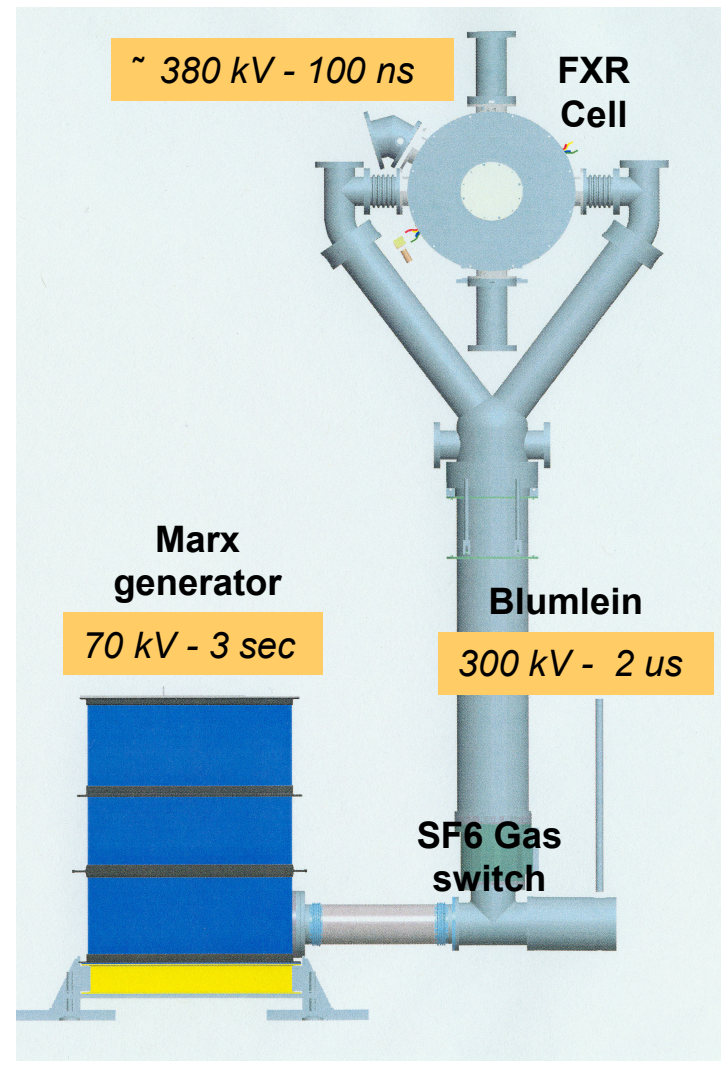

Figure 2: Pulsed Power for FXR 
$S F_{6}$

The Blumlein trigger switches are gas-insulated with sulfur hexafluoride (SF6). SF6 is a strong electronegative molecule so it has an affinity for free electrons. This gives it the highly desirable quality of "quenching" arcs and rapidly recombining when dissociating ("selfhealing".) It has good heat transfer qualities and is relatively free from decomposition at temperatures up to $500{ }^{\circ} \mathrm{C}$

In spite of its inertness, SF6 can react with gas impurities at arc temperatures, the by-products of which can react with switch electrodes resulting in contamination or particulates. This requires gas to be periodically purged via venting and replacement with clean bottle gas. These by-products can also be quite toxic making casual venting of used SF6 problematic.

Although not an ozone-depleting substance (note the absence of chlorine atoms) SF6 is the most potent "greenhouse gas" known with an effective infrared absorption 23,900 times that of an equivalent mass of $\mathrm{CO}_{2}$ [8.] In addition, its atmospheric lifetime is estimated at 3200 years, far in excess of $\mathrm{CO}_{2}$ 's 100 -year life [8.]

Furthermore, the cost of SF6 has increased to about \$2000 US per standard 115-pound bottle.

\section{APPROACH}

For these reasons, FXR began periodically recycling its gas almost 10 years ago and recently an effort was undertaken to upgrade the recycler to permit continuous filtration and to permit more localizized pressure control. We further surmised that recycled gas could, through successive passes through filters, scrubbers, and driers, become cleaner than our standard purchased bottle gas and hence provide more repeatable, better switching, while being environmentally responsible and saving money. Figure 3 shows our skid-mounted compressor unit while Figure 4 shows a typical pressure-regulator setpoint. The system currently has 25 different, independently-adjustable pressure and flow circuits. This permits considerable adjustment in pressure - and hence

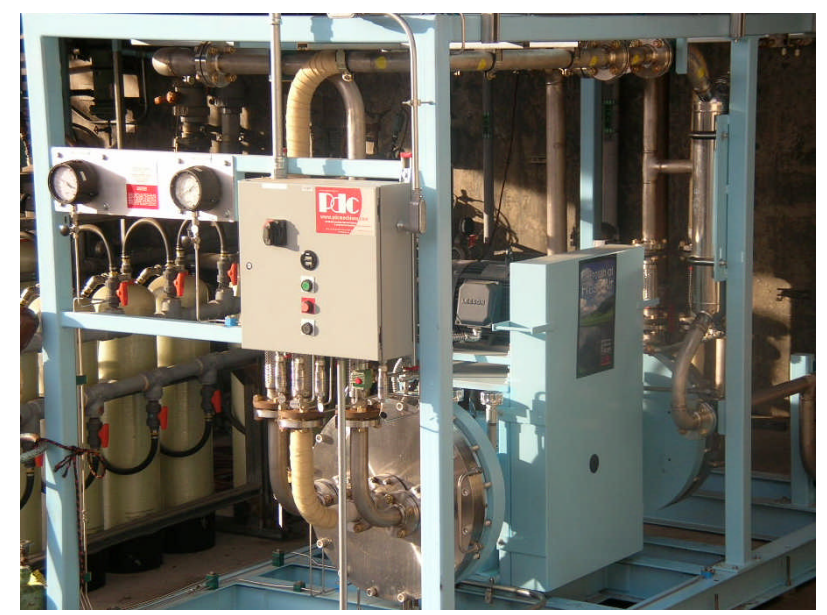

Figure 3: Skid-mounted compressor for SF6 recycling

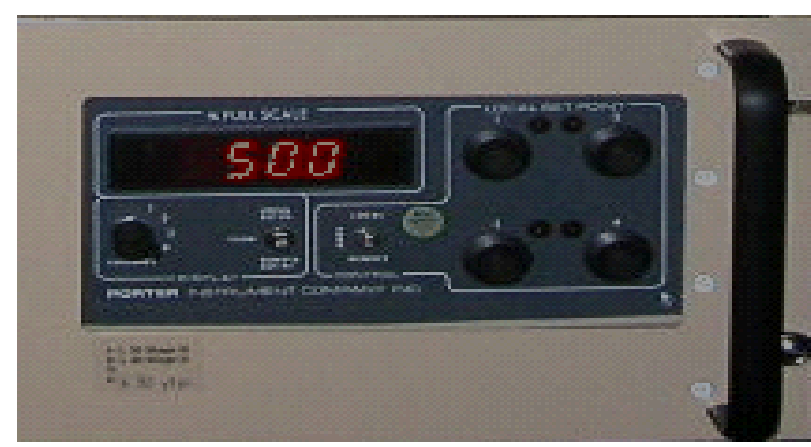

Figure 4: Four-channel pressure-regulation module.

trigger hold-off capability - within the system. (The old system maintained a fixed pressure for all switches.) We expect this will allow us to adjust for switch aging and production variability.

Custom software has been written to permit remote control and monitoring of each channel's performance.

\section{Gas Results}

Moisture content is being continuously monitored at the return tower in the new system via a dew point meter. Water vapor is of particular concern since it provides both the hydrogen and oxygen present in undesired arc byproducts such as $\mathrm{HF}$ and $\mathrm{S}_{2} \mathrm{~F}_{10}$. Within days of commissioning, the unit was recording a moisture decrease from $4 \mathrm{ppm}$ by volume (typical bottle gas spec for "dielectric" or power utility grade gas) to $1.5 \mathrm{ppm}$. Furthermore, in one year of operation since, we have seen steady decrease to $0.1 \mathrm{ppm}$ testifying to the effectiveness of the driers and scrubbers

\section{Accelerator Performance Results}

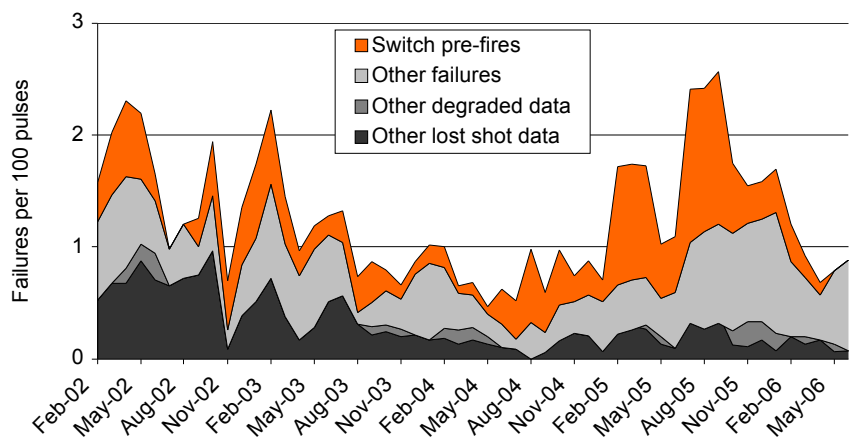

Figure 5: Gas-relative switch failures appear to have greatly diminished since fielding the SF6 reclamation system

Operating FXR entails thousands of accelerator pulses to optimize performance and tune the complex machine. Operations personnel keep records of the occasional failed pulse as a way of tracking reliability. Figure 5 shows a typical representation of such studies. What is noteworthy is that a fairly common problem, name Blumlein trigger switch pre-fires, have dropped to virtually nil since fielding this SF6 recycler system, validating our expectations that cleaner gas is more reliable gas and better accelerator reliability. 


\section{Test Stand Studies}

To further investigate switch reliability and performance, the FXR Test Stand [9] was utilized to provide reliable statistical data of switch performance.

A typical Blumlein closing switch was fielded and 1000 shots fired in a single day at elevated Blumlein charge voltage and decreased gas pressure to provide a significant number of switch pre-fires. The point of switch breakdown (Figure 6) was determined in time and voltage. After verifying no time-dependent trends were evident in the data indicating switch conditioning or aging, the peak voltage results were rank-ordered to simulate a cumulative distribution function of the statistical probability function. Although occurring at less than $10 \%$ probability levels, a distinct tri-modal characteristic is seen in this data. It is thought that this represents 3 distinct areas of the coaxial trigger electrode being exercised in this run.

This data can be extended, with little dependence on the exact theoretical distribution functions fitted (Figure 7) to very low probability levels, normally thought achievable with only million-point data sets, which is of course beyond both the probable switch lifetime and our ability to meaningfully gather data. These low-probability extrapolations can be used to ultimately predict overall system reliability and assist in determining optimal switch maintenance or replacement schedules.
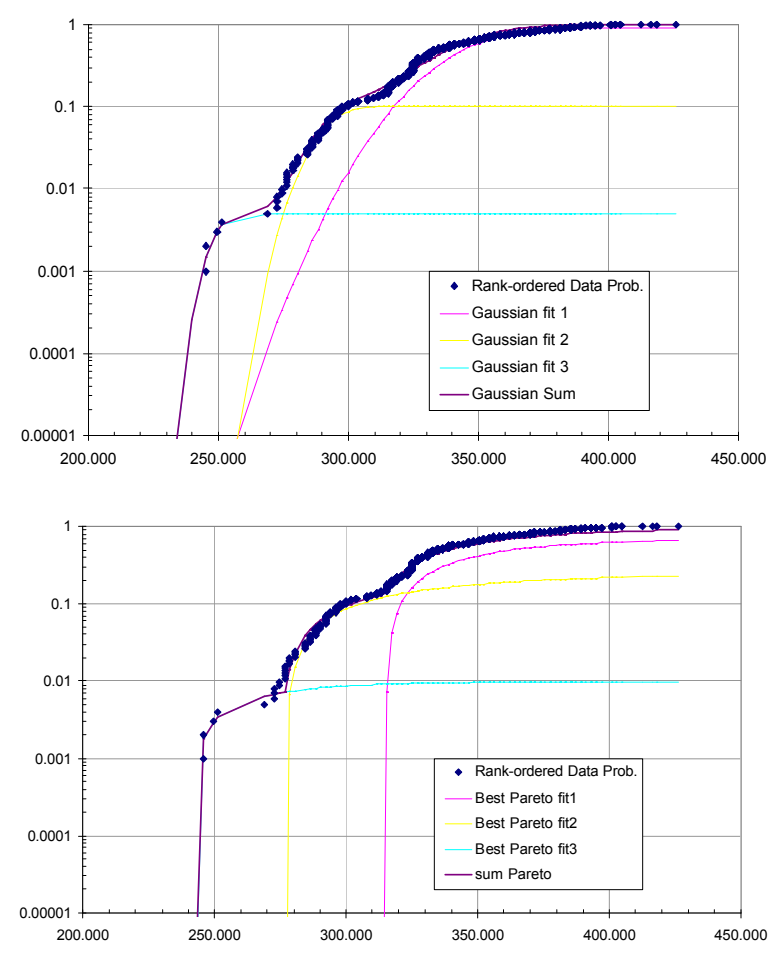

Figure 7: Tri-modal fits using both Gaussian (top) and Pareto (hard-edge, bottom) statistical distributions of experimentally-derived switch breakdown data.

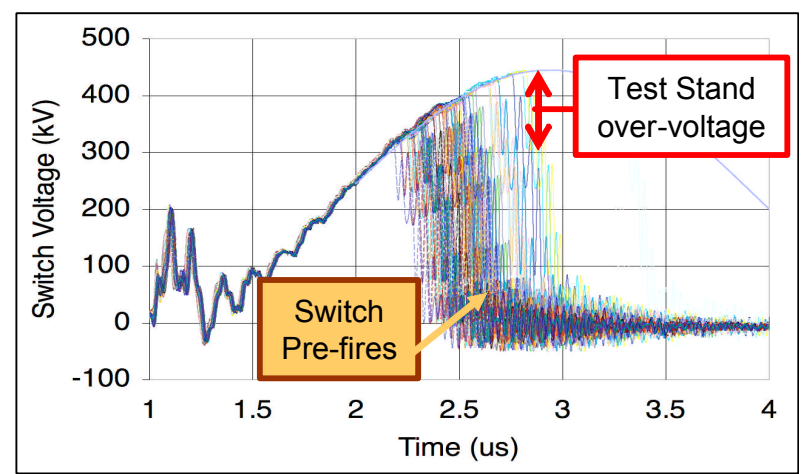

Figure 6: Overlaid pulse traces showing statistical variability in switch breakdown level

\section{CONCLUSIONS}

An SF6 reclamation system was fielded on FXR that offered savings in both cost and environmental impact. It also has demonstrably caused an improvement in accelerator performance and reliability. The FXR Test Stand was used to initiate a quantitative switch reliability study.

\section{REFERENCES}

[1] D. W. Kerst, "The Acceleration of Electrons by Magnetic Induction”, Phys. Rev. 60, 47-53, (1941)

[2] N. C. Christofilos, et al, "High Current Linear Induction Accelerator for Electrons", Rev. Sci. Inst. 35, No. 7, 886-890 (1964)

[3] I. D. Smith, "Induction voltage adders and the induction accelerator family", Phys. Rev. ST Accel. Beams 7, 064801 (2004)

[4] S Yu, "Review of New Developments in the Field of Induction Accelerators" 28th Intl. Linac Conf., August 26-30, 1996, Geneva, Switzerland, http://www.cern.ch/CERN/Divisions/PS/Linac96/

[5] B. Kulke, et al, "Initial Performance Parameters on FXR", in Proc IEEE 15th Power Modulator Symposium, Baltimore, MD, June, 1982

[6] C. Ekdahl, et al, "DARHT-II Long-Pulse BeamDynamics Experiments", in Proc. 2005 Particle Accelerator Conference, Chicago, IL (IEEE, Piscataway, NJ, 2005).

[7] C. F. Baker, "Site 300's New Contained Firing Facility", Science \& Technology Review, UCRL52000-97-3, March, 1997

[8] L.G. Christophorou, J.K. Olthoff, D.S. Green, "Gases for Electrical Insulation and Arc Interruption”, NIST Technical Note 1424, US Dept. of Commerce, November 1997

[9] W. J. DeHope, et al, "An Induction Linac Test Stand" 21st Particle Accelerator Conf., Knoxville, TN, May 16-20, 2005 